Article

\title{
The Branding Potential for the Digital Transmission of Live-Operas to the Cinema: An International Comparison of Estonia and Germany
}

DE DE GRUYTER

OPEN

JULIA ROLL, Tallinn University (visiting), Estonia; email: juro_@web.de

SVEN-OVE HORST, Bauhaus-Universität Weimar, Germany;

email: sven-ove.horst@uni-weimar.de 


\section{ABSTRACT}

Today, opera houses are confronted by new (global) digital media offers that enable people to remain outside the opera house while attending a live-opera, e.g. via livestreamed opera performances in the cinema. This is a challenge for media managers in these fields because they need to find new ways to work with these new opportunities. Within a cultural marketing context, branding is highly relevant. Based on the brand image approach by Kevin Lane Keller (1993), we use a complex qualitative-quantitative study in order to investigate if, and how, the brand images of live-opera performances and live-streamed operas differ between countries and cultural contexts. By comparing Estonia and Germany, we found that the perception of live-opera is rather a global phenomenon with only slight differences. Furthermore, the 'classical' opera performance in an opera house is still preferred, with a corresponding willingness to pay, while the live-streamed opera offer may provide a modern touch. The study may help media managers in adapting their brand management to include new digital product offers and to find targeted differentiation strategies for increasingly competitive markets.

MANAGING LIVE-OPERAS IN

THE CONTEXT OF DIGITISATION

In an era of increasing cultural digitisation, we are currently seeing a wide array of changes in cultural practices and the way in which organisations create cultural products (Gere 2009, Mottart et al. 2004, Reed 2014). Specifically, digital media has altered the way we think of ourselves, the way we consume cultural products, the way we work and the way we conceive the social sphere in general (Creeber, Martin 2009: 5). Here, digitisation refers to software-driven processes, such as datafication, computation, prediction, display, communication or action, which impact all aspects of culture, work and society (Olleros, Zhegu 2016).

As part of this growing digitisation of culture and the social sphere, the impact on music theatres and opera houses is significant. Digitisation and digital media enable people to attend a live-opera event outside the opera house, e.g. by watching digital live-streams in a cinema (Reuband 2013b, Steichen 2013). This is both a challenge and an opportunity for media managers because, on the one hand, they need to develop and make sense of new approaches for branding their new digital goods, concepts and services, and on the 
other, to evaluate how this can influence the consumption and marketability of their existing products and services (Baumann 2013; McDowell 2011; Mierzejewska, Shaver 2014). This is a complex marketing challenge, because it is difficult to understand and judge how this will create opportunities for branding new media products (Weinacht 2015, Wirtz et al. 2011). Meanwhile, sources show that digital live-streams already have an audience. For example, the Metropolitan Opera (MET) of New York, which is the pioneer of live-streamed operas with the most transmissions worldwide, has started turning a profit with tickets costing about $\$ 20$ (Woolfe 2012). Moreover, the company has generated an intangible benefit to its brand perception, adding a touch of innovation to its current service portfolio (Woolfe 2012) and expanding its reach to larger audiences and at a higher frequency (Viagas 2017). Overall, live-streamed operas have a growing relevance (Steichen 2013), in particular, because they are representative of the transformational potential of digitisation among cultural products and services (Creeber, Martin 2009; Reed 2014) and of how they are being presented, consumed and managed as part of an ongoing digitisation process in organisations today (see, e.g., PwC 2016).

Managing this digitisation becomes even more difficult because of the increasing production costs for opera performances and declining normal revenues, as less people attend the regular performances (Abfalter 2010, Lutz 2013, Steichen 2013, Viagas 2017). This trend may be explained by new media usage patterns that influence communication behaviour (Pavlik, Mclntosh 2013), media reception (Manovich 2009) and media preferences (expectations), and that places new demands on the media industry (Küng 2017). Ultimately, they make the management of digitisation a complex strategic problem for media organisations today (Horst, Järventie-Thesleff 2016; Horst, Moisander 2015).

The opera can be defined as a distinct form of theatre, focusing on music. It is a form of 'publicity' that is created in front of a reactive audience and remains selfsufficient (Schäfer 1967: 208). In this sense, it is a medium. Media, here, means an institutionalised system around an organised communication channel that has distinct effects with social implications (Faulstich 2004: 22). Managing these impacts successfully is the hallmark of modern media management (Lowe 2016; Mierzejewska, Shaver 2014).

Against this background, music theatre management is increasingly forced to allocate its resources effectively and efficiently to meet their customers' needs even though opera performances are often valued as an important cultural factor, for which some additional public funding is available (Abfalter 2010: 127, Lutz 2013: 65). Therefore, a market orientation, and especially identity-based, brand management (Aaker 2014, Burmann et al. 2005, Esch 2014) are important approaches that cultural institutions can use for clearly differentiating themselves from their competitors and for building strong customer relationships. Within such an approach, one should distinguish between a brand identity, which is a distinct association that an organisation wants their customers to remember, and a brand image, which is a general association and impression that customers have of an organisation and its offers. Brand images have a strong influence on buying behaviour, because they create positive emotions and values that the organisation is seen to symbolise, and are therefore key elements of differentiation strategies (Hatch, Schultz 2003; Keller 1993: 4).

Even though identity-based brand management provides important tools for managing new digital opportunities for operas, it is surprising to find a current lack of studies addressing this research topic. Moreover, identity-based brand management research widely ignores cultural institutions like opera houses. Most research is focused on specific opera performances or opera houses (Bünsch 2011 and 2015) and deals with either socio-demographic or motivational factors (Abfalter 2010; Föhl, Lutz 2011; Jobst, Boerner 2011; Lutz 2013; 
Reuband 2015). So far, the existing studies that do focus on the type of the opera performance (live-consumed vs. live-streamed) do not take a branding-perspective (Josch 2010, Reuband 2015). Internationally, research has focused on the marketing of opera singers (Jones 2016), but not on the branding of digital live-streams.

The exception is two articles (Emes, Roll 2016; Roll et al. 2017), which used a multi-method study to uncover contextbased and cross-contextual brand associations between an actual live-performance in an opera house and a digital live-stream shown in a cinema. They found that audiences distinguish between the respective brand images in detail. By using multivariate data analysis, they extracted five distinctive brand association factors for each context. However, this cannot provide any information about the relevance of the unique brand association factors or their relevance within the buying process (e.g. the willingness to pay [WTP] for a liveconsumed or a live-streamed opera). Based on a German sample, a second crucial limitation is that the cultural differences are neglected, although scientific research has shown that culture is an influencing factor on human perception and behaviour (e.g. Fetscherin, Usunier 2012; Souiden et al. 2006).

Therefore, the objective of this article is to find out how digitisation influences the branding opportunities for live-operas in music theatre. Our goal is to detect important brand image factors and to provide management recommendations concerning communication, product development and pricing. This is achieved through a comparative international study, conducted in Estonia and Germany. Overall, our contribution will be to show that the integration of the buying behaviour relevance provides more realistic information than only referencing the buying intention (c.f. Emes, Roll 2016). More broadly, this study highlights that economic and cultural factors can be satisfied simultaneously.

\section{THEORETICAL GROUNDING}

The article draws on theories and concepts of identity-based strategic brand management (Balmer 2008, Burmann et al. 2009, Meffert 2012, Phillips et al. 2014b, Voyer et al. 2017). This body of knowledge enables a differentiation to be made between a managerially-intended brand identity (inside view) and the specific brand image (outside view), which reflects all stakeholders' impressions of a brand (Radtke 2013: 2). In the context of increasing competition and digitisation, brands and brand perceptions play a critical role for cultural organisations, because they are crucial drivers for the choices made by consumers (Burmann et al. 2009). In addition, brand identities are important assets because they provide a tangible, yet abstract, representation of the service or product to the customers (Cornelissen et al. 2007, Phillips et al. 2014a, Voyer et al. 2017).

Within this approach, a brand-image can be defined as the shared meaning of the public associations that the related stakeholders have towards the conceptualisation and consumption of the product or service of the cultural organisation (cf. Cornelissen et al. 2007: S3). This view enables us to see the product or service as something that is produced in combination with the stakeholders (Hatch, Schultz 2002 and 2003) and in a larger socio-cultural context (Järventie-Thesleff et al. 2011).

Media branding is unique because of the normative, market and product level aspects (Siegert et al. 2015) and the respective functions regarding the organisation, advertisers and recipients (Baumann 2015). Therefore, in order to construct an understanding of the brand image of an opera, we need to consider the specific qualities of operas as an important cultural product. Operas are services, because of the immateriality of the dramatic music and vocal performance, and because they integrate the external factor of consumption through the audience (Abfalter 2010, Burmann et al. 2005). The audience consumes a media product in both cases - in the opera house and in live-opera transmissions. Moreover, 
the opera has both experience- and trustgood characteristics, which means that it can only be evaluated during or after the consumption, and not before (although some characteristics can never be evaluated at all). However, the individualisation of an opera is more limited than that of other services, because the performance transmission is offered to a restricted or distinct audience. Generally, opera is a form of high culture, which not only needs a degree of involvement and knowledge, but also a relatively high emotionality for the consumer (Abfalter 2010: 64).

Many customer-related uncertainties arise because of this service-character. Therefore, targeted branding activities can be used to create a promise of quality and distinction, which can help to reduce consumers' uncertainties and manage consumption (Malmelin, Moisander 2014). We define a brand as a bundle of benefits that has specific characteristics in terms of identification and differentiation for the relevant target groups (Meffert 2012: 270).

To better understand the brand image, we will now focus on the attendees of liveoperas. We analyse the determinants of the brand image with a behavioural science approach. Furthermore, we presume that brands have characteristics with different abstraction-levels that are part of a larger 'semantic network' (Keller 2005: 1318). Therefore, we will not address a specific event or location. Instead, our focus is on the general contexts of music theatres to derive abstract brand characteristics. The conception of Kevin Lane Keller (2005) is ideal, because it focuses on the brand awareness, as well as the brand image, and highlights the attitude towards a brand as significant success factor. The brand image is the core determinant for customers' preferences and choices and includes unique, advantageous and strong associations (Keller 2005). More specifically, Keller (1993) differentiates between three levels of brand association that have a rising level of abstraction:
1. Attributes. This includes consumer perceptions of the product or service, i.e. what it is or has, and what is involved with the purchase (Keller 1993: 4). They can be differentiated into product-related and non-productrelated characteristics, such as price, user conceptions of the benefits, the utility of the benefits, and the packaging (Keller 1993). We exclude the packaging from our analysis, because a live-opera in an opera house or as digital live-stream in a movie theatre is a service. For Keller (1993), a brand personality is based on a combination of user- and usageimpressions. More specifically, the concept of a brand personality is based on socio-psychological assumptions of peoples' attribution to objects and services. It is 'what makes the brand human' (Aaker, Fournier 1995). This is important, because research has shown that strong brand personalities influence buying behaviour positively (Biel 1993), and, therefore, need to be considered when analysing emotionally-laden services such as live-operas. Our study includes this as a separate determinant.

2. Benefits from needs'satisfaction. The benefits arise from the satisfaction of functional (intrinsic), experiential and symbolic (extrinsic) needs through the consumption (Keller 1993: 4).

3. Attitudinal dimension. Brands create consumer preferences. Those preferences are represented by attitudes towards brands (Keller 2005: 1309). Attitudes themselves 'are defined as consumers' overall evaluations of a brand' (Keller 1993: 4).

Overall, the approaches and conceptions of identity-based brand management in public theatres have received little attention in academic research. Current studies focus on specific opera performances and particular opera houses (for a review see, e.g., Bünsch 2011 and 2015; Föhl, Lutz 2011). 
Research on the perception of audiences of German opera performances addresses sociodemographic or motivational aspects, and not the brand image (Abfalter 2010; Jobst, Boerner 2011; Lutz 2013; Reuband 2015). Other studies that focus on the place of opera performances, e.g. in a warehouse (Roll, Höflich 2014), or approach live-opera transmissions in the context of open-air public viewing (for Austria, see Josch 2010) or cinemas (especially Reuband 2013a, 2013b and 2015) do not integrate any branding aspects.

This article fills a research gap, because it analyses the place and the type of opera performances through contrasting live-operas with live-opera transmissions. Based on the socio-psychological concept that knowledge is structured within a semantic network (e.g. Keller 1993), we do not focus on a specific opera house or performance as a brand, but on the abstract context, by distinguishing a live-opera as performance in the opera house from a live-stream in the cinema. This conceptual move makes it possible to create insights into aspects that can be used more widely (generalisability) than results of a specific context (particularity), and allows a general understanding of brands to be created. Furthermore, concerning the five brand image factors (explained in the next section), we will introduce the conceptual framework of the 'brand image flower' (based on Emes, Roll 2016), which allows us to operationalise the branding opportunities in terms of user preferences.

Current research in this area has several limitations, which this study will be able to overcome. To date, most research is often unpublished, as MA or PhD theses, and is often not based on theory, is unsystematic, too focused (for a review see, e.g., Bünsch 2011 and 2015), and not international (e.g. Emes, Roll 2016; Roll et al. 2017). Moving beyond these limitations, the study draws on exciting international data and cross-country collaboration, and is firmly rooted in the literature on media management and general branding. Furthermore, the study considers the context of live-operas, which allows for the creation of novel insights that can enrich growing discussions and fuel other international research in this area.

To analyse the relevance of the brand image factors within the buying process itself, the study continues with the following research question: What is the brand image of live-operas in opera houses and live-streamed operas in cinemas and how should these brand images be managed? This question includes the following three sub-questions:

(1) What are the important brand image factors for live-operas and relating live-streams?

(2) Can we identify customer segments relating to their buying behaviour based on the perception of livestreamed operas in the respondents' data?

(3) What is the willingness to pay (WTP) related to live-consumed and digitallive-consumed opera performances?

Based on the results of Jutta Emes and Julia Roll (Emes, Roll 2016), we assume that classic live-operas in opera houses are perceived as original, positive, holistic and unique experiences. Concordantly, we propose that an opera performance in an opera house will be preferred by the customers. Furthermore, the perception of a high complexity and low accessibility of the opera house context would be beneficial to the customers respective of the audience. Compared to the cinema, the WTP is supposed to be higher.

\section{CONCEPTUAL FRAMEWORK: THE BRAND IMAGE FLOWER}

Based on the identity-based brand conception (Balmer 2008, Burmann et al. 2009, Phillips et al. 2014b, Voyer et al. 2017) and how a brand image can be conceptualised within a semantic network (Keller 1993 and 2005), we are introducing the model of the brand image flower which we specifically developed for live-operas (Roll et al. 2017). From this theoretical framework, the brand 
image can be conceptualised as an image and meaning of the brand, relating to five elements of the product/service.

The first evaluation category, the vividness of impressions, expresses how much the live-opera is perceived as a stage experience with vivid and complex impressions. Cultural claim refers how much the live-opera is seen as an expression of high culture or cultural education. Peculiarity means how the live-opera is seen as special, inspiring to think about, and authentic. The demand of attention describes the feeling of an always retrievable, passive consumption (alongside) within an informal habit. That means that from a subjective perspective, the necessary level of attention is seen as lower. Accessibility shows how easily accessible, public and familiar the live-opera is evaluated to be. (Figure 1)

\section{METHODOLOGY}

The methodology includes two steps. First, it needs to be determined if the brand image flower that is derived from a German's perception is also suitable for investigating the perception of audiences in other countries, i.e. in our study of Estonians. Guided interviews enable deep insights into the Estonian's view of live-operas to be developed and the brand image flower to be tested, because an interviewer can intensively focus on a single interviewee (Alvesson 2003).

\section{STEP 1: QUALITATIVE} ANALYSIS OF THE RESEARCH

Drawing on previous research (Emes, Roll 2016; Roll et al. 2017) and using focus group interviews to reveal brand image associations, the respective guideline was adapted to a 30-minute guided interview in English. It contains both questions related to free associations and structuring techniques like laddering (Reynolds, Gutman 1988; Reynolds, Phillips 2009), repertory grid (Sampson 1972) and brand personality (Aaker, Fournier 1995; Keller 1993). A supplemental questionnaire contains information about socio-demographics (e. g. age, gender), actual visits and the likelihood of a visit. In early February 2017, and in order to receive a variety of answers, the adult participants were obtained through a snowball sampling (Biernacki, Waldorf 1981), differentiating between gender, education and experience with live-operas. Based on theoretical coding (Glaser, Strauss 2008), the records of the interviews were transcribed and later analysed using QDA software (Atlas.ti).

After completing two preliminary tests of the guided interviews in early February 2017, the interviews lasted until mid-February 2017. On average, they lasted about 35 minutes. The participants all lived in Tallinn (Estonia). While it was possible to interview people of different genders (two females, three males), ages (span 25-64 years, average 38 years) and educational levels (one person with a junior high school certificate and the others with university degrees), the experience with live-operas focused on that of opera houses (occasional visits) and other contexts (four people attend such events at least occasionally).

In summary, all the participants are employed with a middle-level income (€1,001-2,000 net monthly income per household), whereby most are married (3 persons), the others single. While the likelihood of visiting an opera house in the next six months is seen as neutral (3 persons) or rather unlikely (2 persons), it is remarkable that three people rated the likelihood of visiting the cinema as at least rather likely. Also, other contexts will be visited more or less by two persons.

Surprisingly, the Estonian interviewees mentioned all the aspects of brand associations that Keller (1993) describes. Moreover, every attendee describes the opera house and cinema context by using features of all the brand image factors, which proves the relevance of the brand image factors for buying live-opera tickets at the same time. This means that the brand image flower can be used as an instrument to investigate similarities and differences between Germany and Estonia.

Compared to Germany, the contexts are quite similar. However, slight cultural 
easily accessible, public, familiar setting

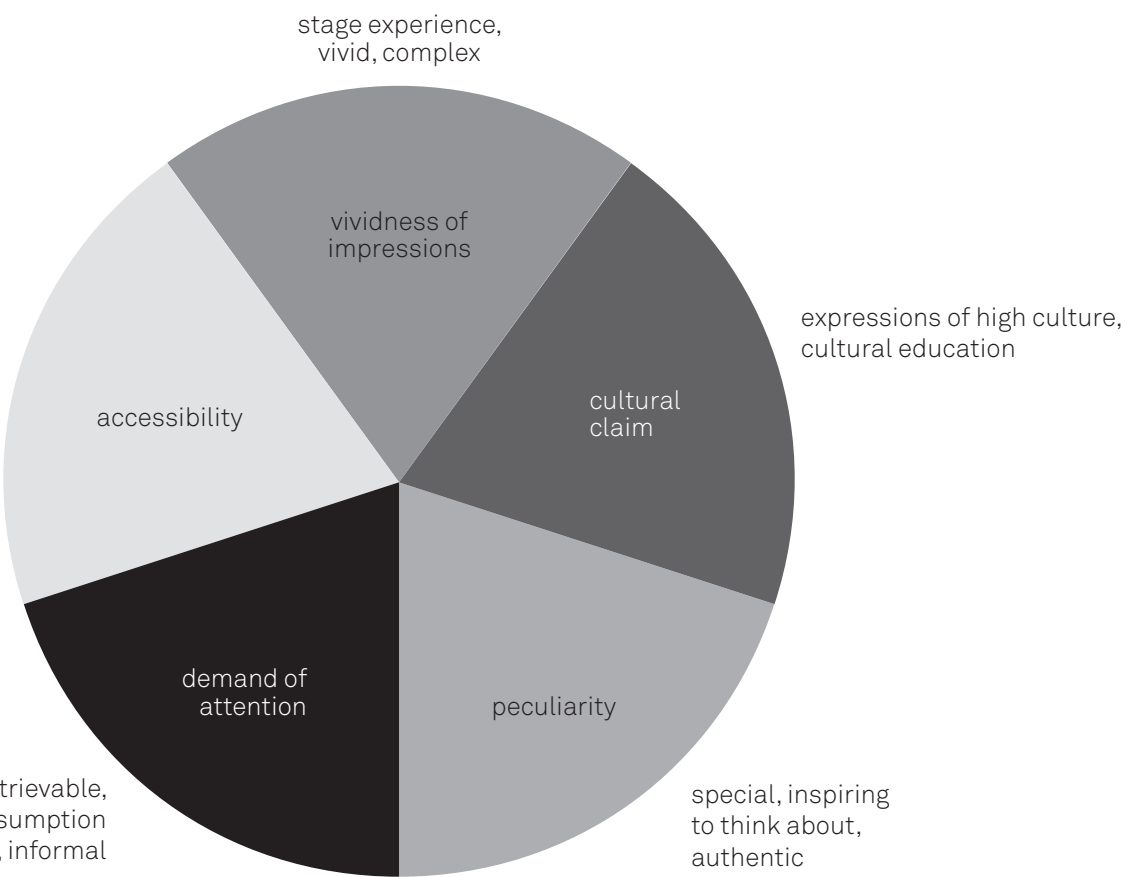

FIGURE 1. Cross-context brand image flower (orienting on Emes, Roll 2016). 
differences compared to the German sample in the study of Emes and Roll (2016) can be detected by the answers of the participants concerning who an opera house or cinema would be as a human being (Emes, Roll 2016). The Estonian attendees characterise the opera house or the cinema not only as an adult male, but as a female, as both or as a couple (the latter applies only to the cinema). A formal dress plays an important role for both. Compared to the opera house, the cinema is described as younger, more fashionable and casual. But in reference to the opera house, the Estonian participants highlight that this character is very dressed up. Furthermore, they emphasise the importance of good looks when describing the cinema as 'handsome' (P3w). While no international differences appear in the factors related to being welleducated and having good manners, the Estonian cinema is seen as more approachable and described as 'more interesting to me' (P5m). At the same time, the experience at cinema is (like in the German sample) not as profound as demonstrated by the participants' claims about it being '2D' (P1 m), 'video-like' (P2w), or it 'wants not to get older' (P3w) or 'sitting right before the people and looking forward' (P4m). This refers to an understanding of the cinema as a copy-like performance without the feeling of becoming really involved/sensually stimulated as is possible in the opera house.

Overall, this suggested that the cinema is more positively rated by Estonians, and therefore, is a competitor for the opera house. Furthermore, this step suggested that there are more segments in Estonia because they make finer distinctions between the contexts.

\section{STEP 2: IN-DEPTH QUANTITATIVE ANALYSIS OF THE SURVEY DATA}

In the second step, an online survey meant to reveal the buying behaviour and enable segmentation, if necessary. For the quantitative data analysis of the online survey, the article adopts common multivariate analytical procedures in order to make sense of the data, but also a choice based conjoint analysis of the brand image factors (Orme 2014). Our methodological approach provides a unique opportunity to explore the factors that are most relevant for deciding whether to attend a live-opera performance or a live-streamed opera performance.

Based on Keller (1993), we asked for the strength, uniqueness and favourability of the factors of the brand image flower in order to gain deeper insights into the evaluation of the brand image. Although the strength and uniqueness of the existing questions of a former study by Emes and Roll (2016) have been proved suitable, we decided to investigate the favourability by using a choice-based conjoint design (CBC). This approach is similar to realistic choice situations, because 'respondents are shown a set of products in full profile and asked to indicate which they would purchase' (Orme 2014: 45). Full profile means that the offers are characterised by different attributes with various levels. A multivariate conjoint analysis can reveal the utility values of the levels, as well as the importance of attributes for the decision (Rao 2014: 9). Presuming a trade-off between the levels and attributes, this method is widely used for product development, pricing or segmentation (Orme 2014: 22). In our study, the important, independent, realistic and influenceable attributes with their levels include type (live-opera performance vs. livestreamed opera), price (€15/€25/€35/€45) and the brand image flower aspects (high/ middle/low). Regarding the CBC design, the participants were repeatedly asked to choose one of three offers with varying levels of all the attributes, or the 'no purchase' option, which is offered at the same time. One of the six choice sets of our study is defined as a holdout task. Such a holdout task enables the predictive validity of the estimated utility values to be checked and it is not used for the estimation of consumers' preferences (Orme 2014: 16). In addition, variables like attitude, socio-demography (e. g. age, gender) and actual visits have proven suitable for describing the sample. Even if the questions of the online questionnaires 
for both countries are the same, each is in the mother language to prevent distortions. After developing the online questionnaire with the Sawtooth Software, online platforms, social media (e. g. Facebook), mailing lists and self-selection on websites were used to recruit participants in February and March 2017. An incentive ( $€ 10$ for a popular online merchant) was used to attract participants. Figure 2 delineates

the methodological approach.

Based on the results of the guided interviews, and after five preliminary tests of the online questionnaire, we collected 118 Estonian and 99 German usable datasets in February and March 2017. Both samples contain more females (EE $83 \%$, GE 61.6\%), have a higher education with at least a university degree (EE 81.4\%, GE 69.7\%), have balanced income levels and are mostly employed (EE 72\%, GE 67.7\%) or studying (EE 22\%, GE 26\%). Furthermore, it is quite a young sample ( $E E: M=39.7$, $S D=13.76$, range from 20 to 76 years; $\mathrm{GE}: \mathrm{M}=34.57, \mathrm{SD}=11.12$, range from 21 to 73 years).

It is remarkable that within the Estonian sample $95.1 \%$ attended a live-opera in the opera house at least once, $144.9 \%$ a live-streamed opera in the cinema and 83.1\% a live-opera in another location. In contrast, the German participants have experience related to the opera house (88.9\%), but less related to the cinema $(17.2 \%)$ or other locations (38.4\%). When looking at the intention to visit within the next six months ${ }^{2}$ we see that the Estonian participants rate an opera house visit as more likely $(M=2.61, S D=1.301, n=118)$ than the German sample who saw it more neutral ( $M=2.8, S D=1.400, n=99)$. Similarly, the Estonian sample evaluates the visit to the cinema and other places as neutral $(M=3.46, S D=1.363$ vs. $M=3.27, S D=1.432$, $\mathrm{n}=118$ ), while the German participants' visits of those contexts is rather unlikely $(M=4.2, S D=.937$ vs. $M=4.02, S D=1.010)$.

1 Scale: $1=$ several times a month, 2 =monthly, $3=$ several times a year, $4=$ rarely, $5=$ almost never, $6=$ never.

2 Scale: $1=$ very likely, 2 =rather likely, $3=$ neutral, $4=$ rather unlikely, $5=$ very unlikely.
It is remarkable that visits to other places are slightly more likely than to go to the cinema in both samples. Therefore, the opera houses are ranked most positively (EE: $M=1.95, S D=.601, n=118 ; G E: M=1.87, S D=$ $.750, n=99)$. Interestingly, the Estonians rank the cinema as rather positive $(M=2.43$, $\mathrm{SD}=.743, \mathrm{n}=118$ ), whereas the German participants have a neutral opinion $(M=3.03$, $\mathrm{SD}=.706, \mathrm{n}=99$ ).

\section{RESULTS \\ Brand image profiles}

Concerning the perceived strength of the opera house brand image, it is striking that the profiles are quite similar. While being almost congruent with high values for the vividness of impressions, cultural claim and peculiarity; some differences occurred in the demand of attention and the accessibility. The German sample gave both brand image factors a slightly lower and mid-levelled rating than the Estonian participants. The Estonian interviewees see the demand of attention as mid-levelled, but the accessibility as high. In contrast, the cinema perception is more mid-levelled, while the Estonian sample reveals marginally higher values. (Figure 3 )

However, the perceptions of uniqueness by Estonians and Germans do not differ. Presuming that at least $50 \%$ of the respective sample mention the brand image factor as unique, the opera house is characterised by vividness of impressions, cultural claim and peculiarity. The unique factor of the cinema is accessibility.

\section{Customer segmentation}

The preference related to the favourability of the brand image flower in combination with the type and price of a live-opera ticket was conducted via CBC analysis. The assumption, that there are significant differences in the preference profiles and that segmentation is necessary, could be proved for both countries. A latent class analysis ${ }^{3}$ algorithm to estimate the part-worth utilities. With exception of the price (it turned out that a linear model delivers better values), all utility parameters were 
'for segmenting respondents into relatively homogeneous groups, based on preferences' (Orme 2014:35) revealed a significant twocluster-solution for both countries $(p<0.05)$.

In each country, there is a larger (EE cluster 1: $n=79$, GE cluster 1: $n=67)$ and a smaller cluster (EE cluster 2: n=39, GE cluster $2: n=32)$. While the age of the German sample is at the same level (average age of cluster 1 is 34.48 years, of cluster 2 it is 34.75 years), the Estonian cluster 1 is slightly older (40.59 years vs. 38.0 years).

At this point, the question arises: Apart from differing preference profiles, are there significant differences ${ }^{4}$ related to variables like actual visits, likelihood of visits, attitude and socio-demographics (e.g. age, gender)? It is striking that in the Estonian sample only actual visits of the opera house and cinema (cluster 1 attends both contexts more often) as well as the likelihood to attend a live-opera at the opera house or cinema within the next six months (cluster 1 is more likely to visit) differ significantly ( $p<0.05)$. Similarly, within the German sample, the actual visits of an opera house and other places (cluster 1 attends the opera house less frequently than other places) as well as the likelihood of the visit of a cinema or other places (cluster 1 is more likely to go) produces significant values $(p<0.05)$.

\section{Impact on buying behaviour}

An overview of the importance of the brand image factors reveals many similarities. Cluster 1 of both the Estonian and German sample sees the vividness of impressions (25.2\% vs. $28.5 \%$ ), followed by the cultural claim (21.4\% vs. $20.1 \%$ ) as the most important factor for their decision to buy tickets for an opera house or cinema visit. While, in third place, the Estonian participants focus on peculiarity (16.3\%), the German attendees look at type (15.5\%). The price of opera

estimated by using a part-worth utility model. Furthermore, neither the Estonian nor the German sample contains relevant interaction effects between attributes and levels $(p<0.05)$. Therefore, the results are based on the main effects.

4 Depending from the scale level, the variables were checked by using Pearson's chi-squared test, likelihood-test, or an ANOVA. tickets plays only a minor role, which is in sharp contrast to cluster 2 in each country (32.3\% vs. 25.8\%). In cluster 2, the Estonian interviewees consider the demand of attention next (19.5\%); for German participants it is type (21.1\%). For the Estonians, type is in third place (14.3\%); for the German sample it is peculiarity (16.9\%).

A crucial finding is that the ideal opera-house- vs. cinema-offer, which is defined by the level of each attribute with the highest utility value (Orme 2014:81), does not differ. All the clusters of each country prefer the opera house ticket with a lower price, and highly value the brand image factors of vividness of impressions, cultural claim, peculiarity and demand of attention. Only accessibility is evaluated differently - with the exception of Estonian cluster 1, which prefers high value, all the other clusters see a middle level as most preferable. (Figure 4)

Concerning the perceived strength of the brand image flower, there are few significant differences $(p<0.05)$. While the Estonian clusters can be differentiated by the perception of the vividness of impressions and the accessibility of the opera house (cluster 2 has slightly lower values), the German clusters are characterised by the evaluation of the cultural claim of the cinema (also cluster 2 has lower values). The uniqueness of the brand image factors has no significant differences within the German sample. The cluster of the Estonian participants has a significant result related to the cultural claim of the cinema. However, by presuming that at least $50 \%$ of the participants would rate the factor as unique, the cultural claim of the cinema with values about $40 \%$ is not relevant.

\section{Willingness to pay}

In order to investigate the WTP for a liveopera in a competitive environment, we used a market simulation based on a price response function. The price response function indicates the share of preference ${ }^{5}$ as

The share of preference is based on a logit model. The values of all alternatives sum up to $100 \%$. 

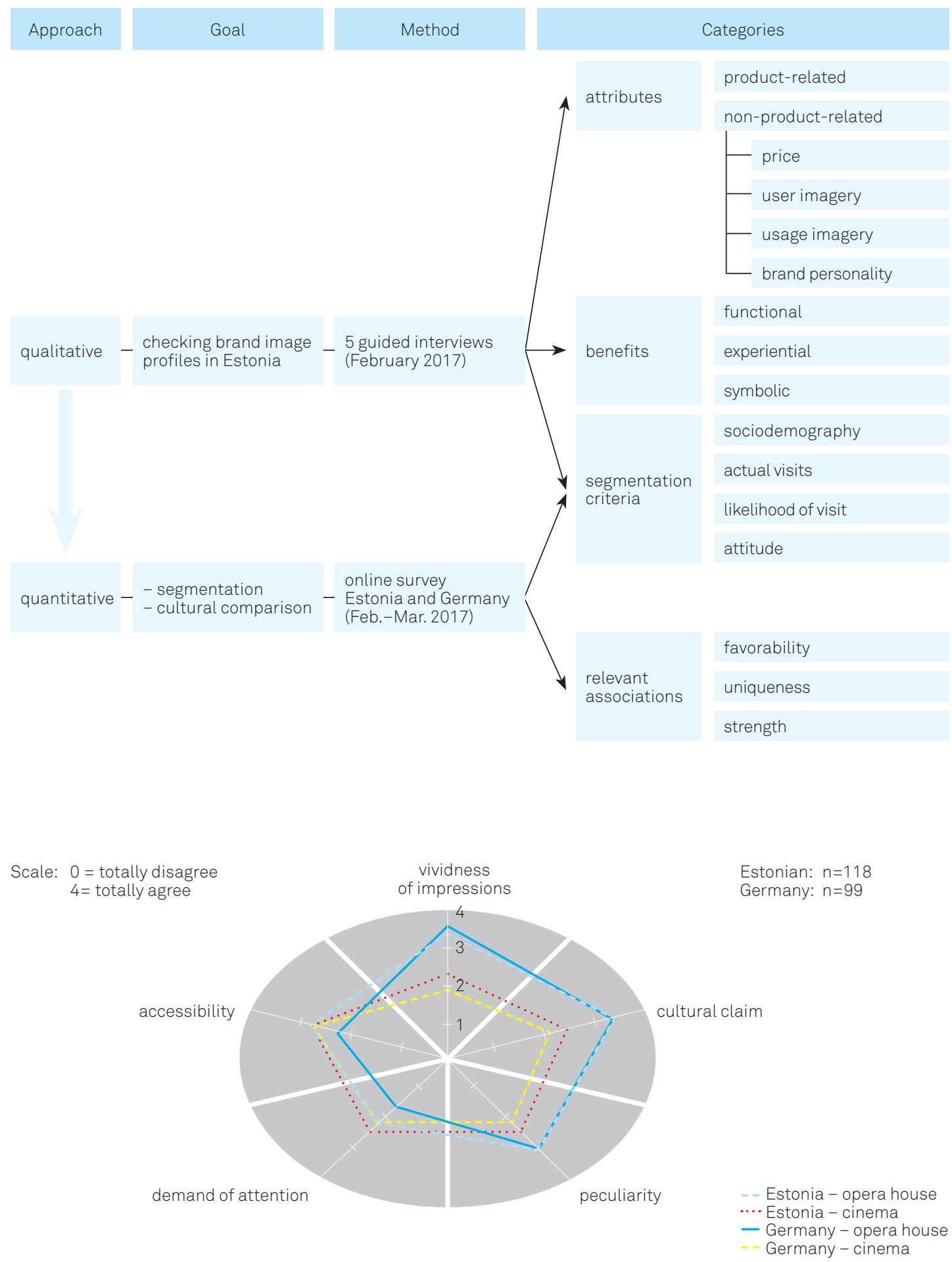

FIGURE 2. Research design (original research).

FIGURE 3. Perceived strength of the brand image factors (original research). 
the selection probability of a specific offer, when the prices of this specific offer are varied while the competitive offers are holding constant (Backhaus et al. 2015: 250, Orme 2014: 88). Such an approach offers two main advantages. On the one hand, it is possible to derive monetary utility values; on the other hand, we can analyse price effects in a relatively realistic scenario (Backhaus et al. 2015: 250).

We defined the relevant market for our simulation as following: First, we used the values of the current perception of the liveopera performance and the live-streamed opera (Figure 3) and assigned them to the three levels (low-middle-high), which were already used for the CBC design. This enabled us to use the corresponding utility values of Figure 4. Furthermore, we estimated the part-worth utility value of the price by using the realistic average price for liveopera tickets (for Estonia €20, for Germany $€ 30)$ like in the CBC design. Second, we integrated a 'no purchase' option with a utility value and price (respective WTP) of zero as an alternative reference (see also Backhaus et al. 2015: 251). A separate simulation was run for each cluster.

Assuming that only positive benefits lead to a specific WTP level (Gensler et al. 2012: 372), both the Estonian and German clusters 2 do not have any WTP because the benefit values for opera house and cinema tickets are negative. In contrast, cluster 1 for both countries show partly positive benefits. The monetary gross benefit related to the WTP for opera tickets of the Estonian cluster 1 is $€ 19.97$ (intersection point of the opera house and 'no purchase' function, Figure 5). However, the monetary net benefit as the difference between the monetary gross benefit and the typical price (for Estonia $€ 20$ ) reveals a negative value of $-0.03 €$. That means that opera tickets are at least €0.03 too expensive. Comparing opera house to cinema tickets, there is a positive monetary benefit difference of $€ 10.84$ (the difference between the value of the intersection point of the opera house and cinema tickets and the determined price of $€ 20$ for cinema tickets), i.e. opera house tickets are preferred. Moreover, the share of preference for the 'no purchase' option is always higher than that for cinema tickets. This is an indication that cinema tickets are also too expensive. Furthermore, the Estonian cluster 1 seems to be quite price sensitive, because the gradient of the opera house function is quite high. Therefore, by increasing the price, the share of preference decreases fast (Figure 5).

Looking at the price response functions of German cluster 1, there is a quite similar result. While being less price sensitive than Estonian cluster 1, the WTP for opera tickets is €45.27. Based on a typical price offer of $€ 30$ per opera house ticket, the net monetary benefit is positive, so that the participants would spend €15.27 more. Here too the opera house tickets are preferred to cinema tickets and result in a positive monetary benefit difference of $€ 28.80$. However, cinema tickets are still too expensive because the share of preference for the 'no purchase' alternative is higher at all price levels (Figure 6).

As outlined above, we revealed slight differences between the current perception and the ideal related to the most preferred opera house brand image. That is, it is only the demand of attention that is ranked as middle level, but preferred as high level this means, a live-opera performance is preferred more when it is seen as being more passively consumed (along with) within a more informal habit (Figure 7).

In this context, the question arises what happens when an opera house is able to change the perception of the demand of attention to the ideal level (i.e. consuming a live-opera is not a challenge for information processing) and to increase the benefit. In regard to Estonian cluster 1, we can see a slight improvement of the WTP to $€ 21.59$. This means a positive monetary net benefit of $€ 1.59$ (based on a €20 ticket), but only a minor increase of $€ 0.44$ of the monetary benefit difference to the current perception of the opera house and the cinema. However, because of the positive net benefit, the participants of cluster 1 would now buy opera house tickets for $€ 20$. 


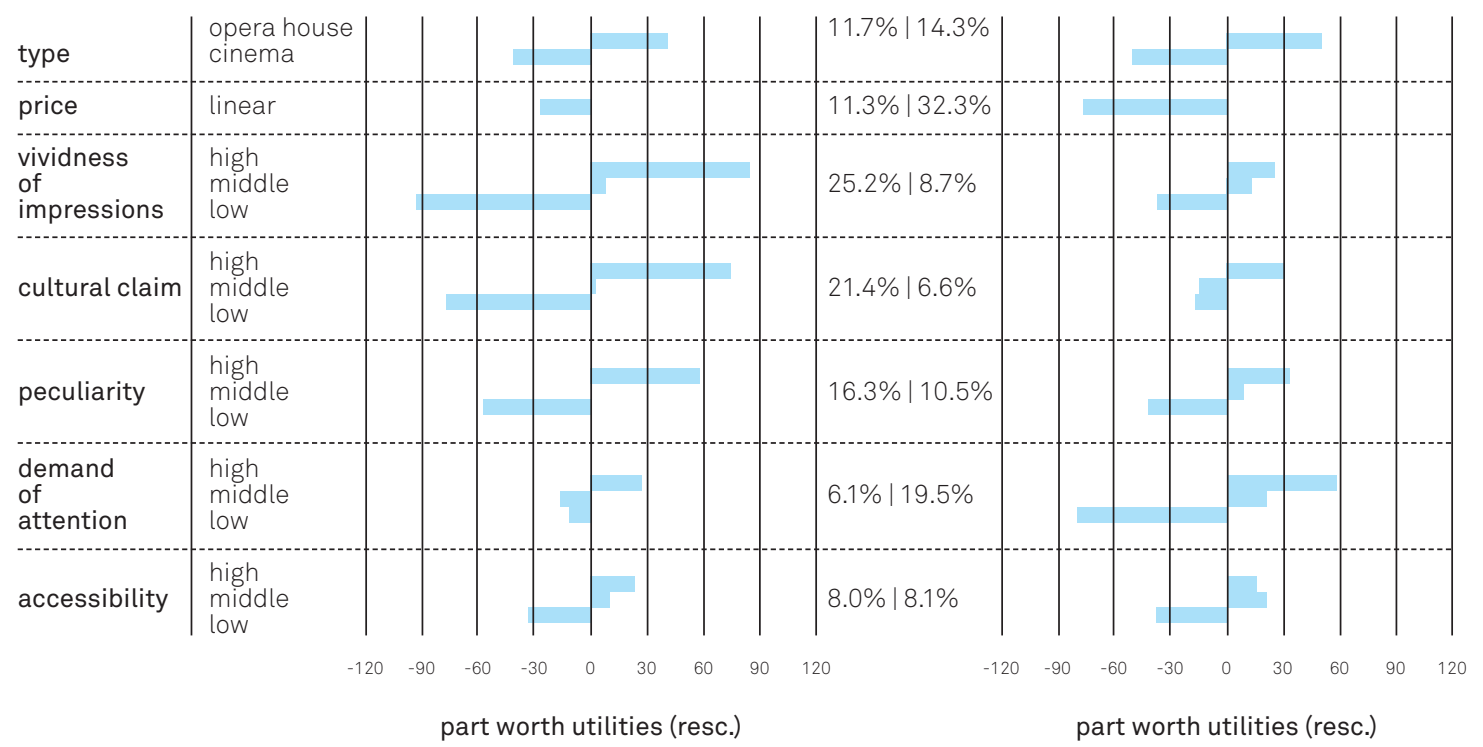

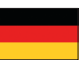

Germany: $n=99$

Cluster $1(n=67)$

Cluster $2(n=32)$

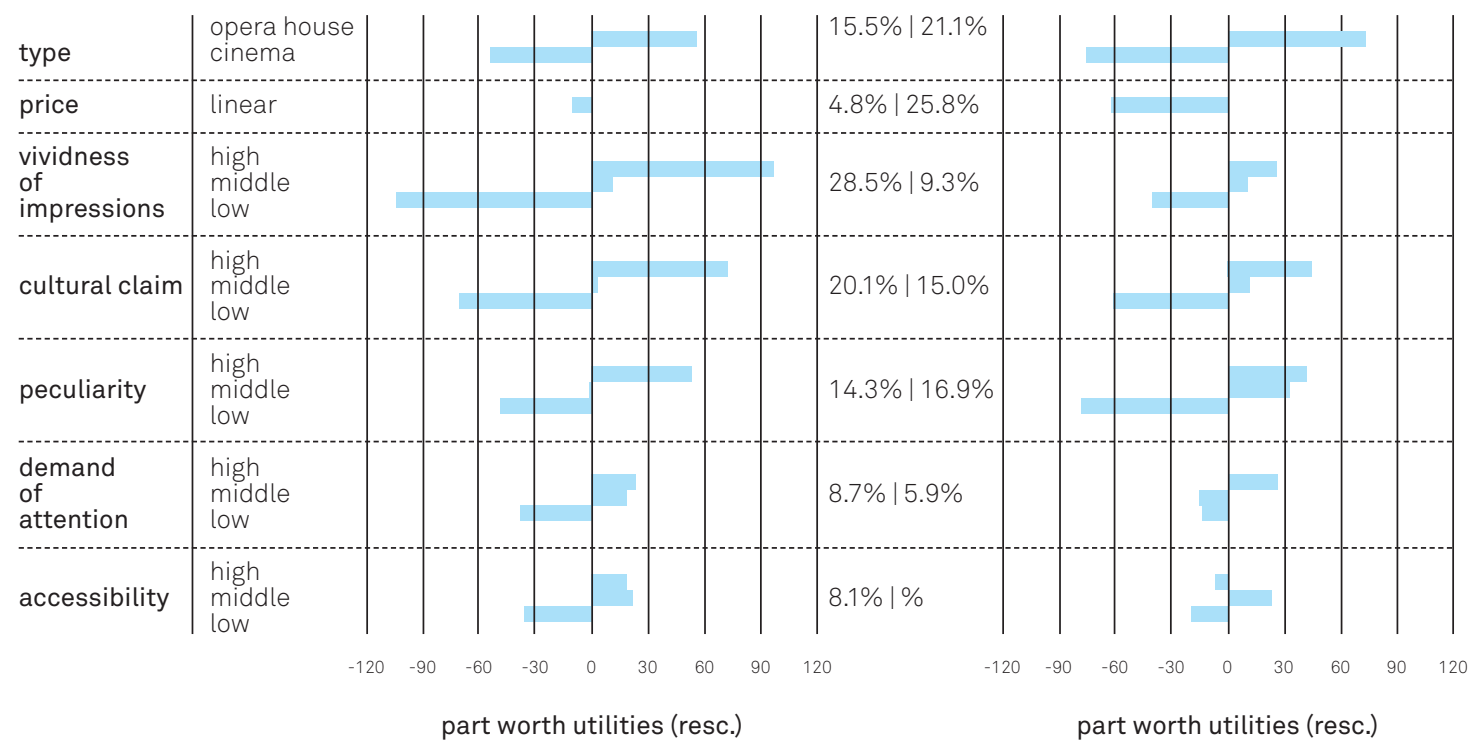

FIGURE 4. Part-worth utilities and attribute importance (original research). 
With $€ 45.71$, the increase of the WTP of German cluster 1 is also quite low. With a positive net benefit difference gain of $€ 1.62$ for opera house tickets compared to the current perception of the opera house and cinema, the attendees would still buy opera house tickets.

Looking at cluster 2 of both countries reveals that the negative benefits are slightly decreased by the ideal opera house brand image, but they still have negative values. Therefore, both clusters do not have any WTP.

At this point, it is not only important to consider the (in this case quite limited) gains in WTP. Rather, it is necessary to relate those results to the relative importance possessed by the brand image factor demand of attention. Similarly, with exception of Estonian cluster 2, there is quite limited importance of about $7 \%$ for demand of attention. That means that this factor is only of minor importance for the decision to buy live-opera tickets.

\section{DISCUSSION AND CONCLUSION}

We have shown that the integration of buying behaviour relevance provides more realistic and deeper information than only referencing the buying intention. The managements of opera houses can use these results to develop targeted brand management strategies for communication, product development and pricing. In a broader sense, this study highlights that economic and cultural factors can be satisfied simultaneously.

Concerning the brand image profiles, we can confirm the results of Emes and Roll (2016). Moreover, we found that the perception of live-opera is a global phenomenon with only slight differences between countries. While there are similar profiles for the perceived uniqueness and strength (Keller 1993) of the brand image flower, significant differences can be detected in favourability (Keller 1993) related to part-worth utilities. Based on part-worth utilities, two clusters were distinguished in each country. This is contrary to the suggestion that the Estonian sample has more clusters because of the heterogeneity of the characterisation of the opera house and cinema context in the guided interviews. Another surprising finding was that, in respect to sociodemographics, attitudes, actual visits or the visit intention, there are only a few significant differences between the clusters. Only actual visits and the visit intention show any significant differences.

Furthermore, it is remarkable that the price, at least for cluster 1 for both Estonians and Germans, is not the most important factor when making the decision to buy tickets. This suggests that live-opera performances in opera houses are valued as important cultural goods. In accordance to Emes and Roll (2016), high accessibility is less preferred. That means that a live-opera visit is appreciated when it is not entirely public or in a familiar setting, but there is a bit of distance. However, Estonian cluster 1 prefers high-levelled accessibility while the other clusters appreciate a middle level. This could be related to the experience at opera house performances, which $95.1 \%$ of the participants have attended at least one time, and $31.4 \%$ several times a year.

A surprising finding was that digitisation does not substitute for opera performances, and instead, creates a complementary media service through live-streams in other places like cinemas. The ideal preferred brand image is almost the same as the current perception of the opera house in both countries. This indicates that people of both countries can be attracted by the classic perception of an opera house. Additionally, the importance of the demand of attention factor, with the exception of cluster 2 in Estonia, is not very high. Therefore, activities to change the perception of the demand of attention should be considered carefully by examining the trade-off. In addition, it could be useful for an opera house to change the perception of the demand of attention to a higher level (i.e. consuming live-opera is not a challenge for information processing), when it aspires to connect this perception to itself. This enables a differentiation from other opera houses and higher benefit increases in the 


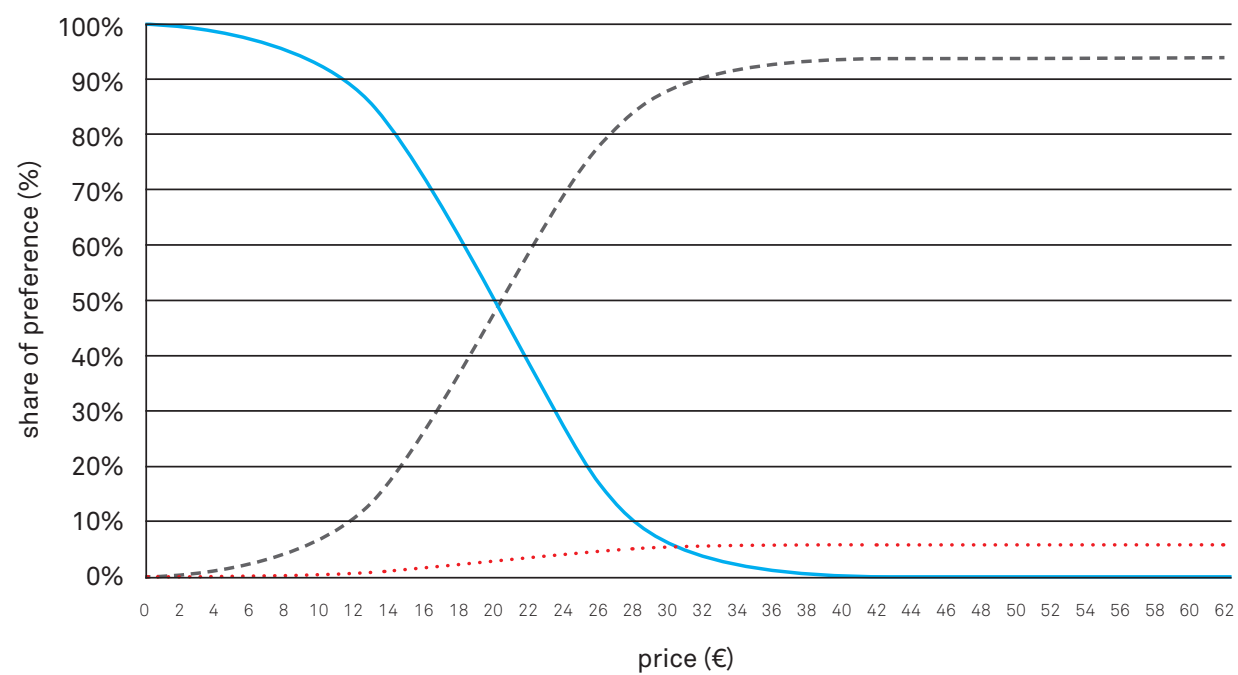

- opera house

- - no purchase

-... cinema

Germany: $\mathrm{n}=99$ Cluster $1: n=67$

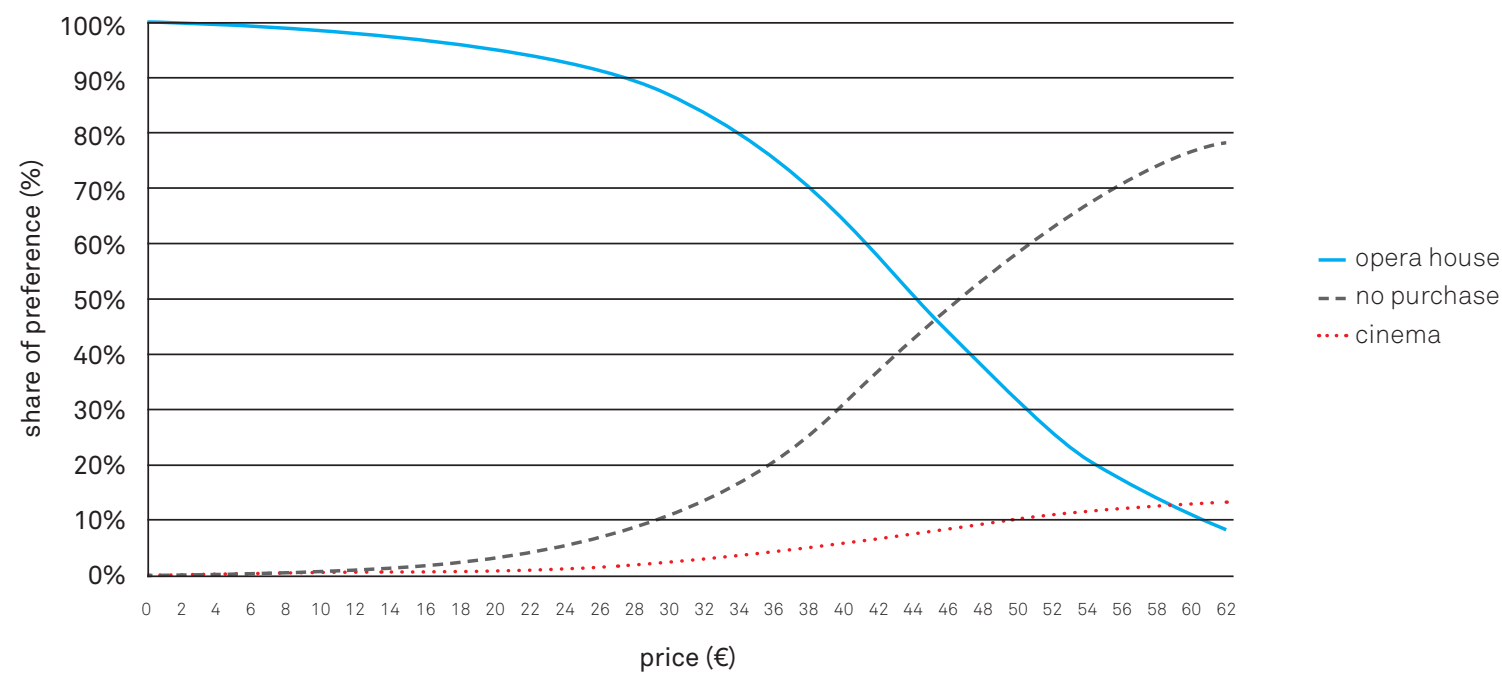

FIGURE 5. Price response functions for live-opera tickets of the Estonian cluster 1 (original research). FIGURE 6. Price response functions for live-opera tickets of German cluster 1 (original research). 
share of the preference - customers are more likely to use this specific offer.

It is surprising that opera house performances are preferred, because in other areas of media, digitisation has huge effects that often lead to transformational changes in work practices, organisational strategies and business models (Baumann 2013, Doyle 2013, Evens 2010, Küng 2017, Vukanović 2016). Moreover, we suppose that digitisation affects opera houses through generating positive effects by widening the spectrum of possible opera customers and creating a 'modern touch' in an otherwise rather classical medium (Steichen 2013, Woolfe 2012). Considering the fact that many people do not currently know about the possibilities of attending live-opera streams (Steichen 2013, Viagas 2017) and that such operas are a service that has to be experienced in order for the quality to be evaluated, we have assumed that even if the WTP for cinema tickets is zero in our study, it is still too early to predict any possible positive or negative consequences. Rather, live-opera streams exemplify a valuable diversification in the business model (Vukanović 2016). With this strategic move, opera providers can innovate their services (Baumann 2013) and market their strengths effectively.

However, several limitations restrict the informative value of our study. First, it is based on small samples. Moreover, influencing factors like the performance, specific opera houses, or motives have not been considered. For further investigation, we recommend integrating the detailed context and checking other countries for similarities and differences. Another limitation is inherent to the CBC itself. It only allows collecting data about part-worth utilities on an aggregated level. To investigate preferences in greater detail, a traditional conjoint analysis can provide data on an individual level (Orme 2014: 30). Furthermore, a common problem of online surveys is the selfselection effect (Bethlehem 2009: 277). Additionally, opera visits are connected to strong emotions, as the guided interviews and the comment field of the online questionnaire suggest. Therefore, we suppose that our samples are predominantly comprised of opera fans. Other methodological approaches like paper-and-pencil questionnaires would enable an examination of other groups. Finally, some participants do not currently know about the livestreams of operas in cinemas. Based on the fact that live-operas are a service, the quite low utility values of live-streamed operas in the cinema could be based on having no experience with this context. It would be valuable to contrast people with and without experience in order to gain deeper insights.

Overall, the study breaks new ground because it analysed how digitisation can impact the consumption of opera performances in new ways. Because operas are a central element of our culture and heritage, the fact that live-opera performances are generally preferred to live-streams is an exceptional finding. This is significant because it means that some customer groups are always willing to pay (high) prices for attending operas. In terms of management opportunities, the study shows that opera houses can benefit from diversification by introducing new product offerings, which may help them gain new customer segments. In turn, this may create significant opportunities for new marketing campaigns and media service branding. And it may, at least for now, reduce the fear that classical operas have about the threats of digitisation and instead help them to focus on the possibilities to build even stronger brands and reach new audiences in society.

\section{ACKNOWLEDGEMENT}

We are very grateful that Louise Flensburg Lend assisted us with an Estonian translation of the German online survey and important notes on our English qualitative interview guide. 


\begin{tabular}{|c|c|c|c|c|}
\hline $\begin{array}{l}\text { Opera House: } \\
\text { current vs. ideal level }\end{array}$ & $\begin{array}{l}\text { Cluster } 1 \\
(n=79)\end{array}$ & $\begin{array}{l}\text { Cluster } 2 \\
(\mathrm{n}=39)\end{array}$ & $\begin{array}{l}\text { Cluster } 1 \\
(\mathrm{n}=67)\end{array}$ & $\begin{array}{l}\text { Cluster } 2 \\
(n=32)\end{array}$ \\
\hline $\begin{array}{l}\text { vividness } \\
\text { of impressions }\end{array}$ & high / high & high / high & high / high & high / high \\
\hline cultural claim & high / high & high / high & high / high & high / high \\
\hline peculiarity & high / high & high / high & high / high & high / high \\
\hline $\begin{array}{l}\text { demand } \\
\text { of attention }\end{array}$ & $\begin{array}{l}\text { middle / high } \\
\text { (importance: 6.1\%) }\end{array}$ & $\begin{array}{l}\text { middle / high } \\
\text { (importance: 19.5\%) }\end{array}$ & $\begin{array}{l}\text { middle / high } \\
\text { (importance: 8.7\%) }\end{array}$ & $\begin{array}{l}\text { middle / high } \\
\text { (importance: 5.9\%) }\end{array}$ \\
\hline accessibility & high / high & middle / middle & middle / middle & middle / middle \\
\hline
\end{tabular}

FIGURE 7. Comparing the current and ideal brand images (original research). 


\section{REFERENCES}

Aaker, David A. 2014. Aaker on Branding: 20 Principles

That Drive Success. New York: Morgan James.

Aaker, Jennifer; Fournier, Susan 1995. 'A Brand as a

Character, a Partner and a Person: Three Perspectives on the Question of Brand Personality'. - Advances in Consumer Research: Proceedings of the Association for Consumer Research 22, 391-395.

Abfalter, Dagmar 2010. Das Unmessbare messen? Die Konstruktion von Erfolg im Musiktheater. Wiesbaden: VS Verlag für Sozialwissenschaften. Alvesson, Mats 2003. 'Beyond Neopositivists, Romantics, and Localists: A Reflexive Approach to Interviews in Organizational Research'. - Academy of Management Review 28, 1, 13-33.

Backhaus, Klaus; Erichson, Bernd; Weiber, Rolf

2015. Fortgeschrittene multivariate Analysemethoden. Eine anwendungsorientierte Einführung. Heidelberg: Springer Gabler

Balmer, John M. T. 2008. 'Identity Based Views of the Corporation: Insights from Corporate Identity, Organisational Identity, Social Identity, Visual Identity, Corporate Brand Identity and Corporate Image.' European Journal of Marketing 42, 9/10, 879-906. Baumann, Sabine 2013. 'Adapting to the Brave New World: Innovative Organisational Strategies for Media Companies' - Tanja Storsul, Arne H. Krumsvik (eds.), Media Innovations: A Multidisciplinary Study of Change. Göteborg: Nordicom, 77-92.

Baumann, Sabine 2015. 'Media Branding from an Organizational and Management-Centered Perspective.' - Gabriele Siegert, Kati Förster, Sylvia M. Chan-Olmsted, Mart Ots (eds.), Handbook of Media Branding. Cham: Springer International, 65-80.

Bethlehem, Jelke G. 2009. Applied Survey Methods: A Statistical Perspective. Chichester: John Wiley \& Sons. Biel, Alexander L. 1993. 'Converting Image into Equity'. David A. Aaker, Alexander L. Biel (eds.), Brand Equity and Advertising: Advertising's Role in Building Strong Brands. Hillsdale: Lawrence Erlbaum Associates, 67-82. Biernacki, Patrick; Waldorf, Dan 1981. 'Snowball Sampling: Problems and Techniques of Chain Referral Sampling.'- Sociological Methods \& Research 10, 2 , 141-163.

Bünsch, Nicola 2011. 'Markenbildung für Theaterbetriebe. Forschungsstand und Perspektiven'. - Steffen Höhne, Nicola Bünsch, Ralph Ziegler (eds.), Kulturbranding III. Positionen, Ambivalenzen, Perspektiven zwischen Markenbildung und Kultur. Leipzig: Universitätsverlag, 101-123.

Bünsch, Nicola 2015. Profil ja, Marke nein? Profilierungsstrategien öffentlicher Theater- und Opernbetriebe im Kontext der Debatte um Markenbildung im Kulturbereich. Eine interdisziplinäre und fallvergleichende Analyse. Weimar: Bauhaus-Universität Weimar. Burmann, Christoph; Jost-Benz, Marc; Riley, Nicola 2009. 'Towards an Identity-Based Brand Equity Model'. - Journal of Business Research 62, 3, 390-397. Burmann, Christoph; Schleusener, Michael; Weers, J.-P. 2005. 'Identitätsorientierte Markenführung bei Dienstleistungen'. - Heribert Meffert, Christoph Burmann, Martin Koers (eds.), Markenmanagement. Identitätsorientierte Markenführung und praktische Umsetzung. Wiesbaden: Gabler, 411-432.

Cornelissen, Joep P.; Haslam, Alexander S.; Balmer, John M. T. 2007. 'Social Identity, Organizational Identity and Corporate Identity: Towards an Integrated Understanding of Processes, Patternings and Products'. British Journal of Management 18, S1, S1-S16. Creeber, Glen; Martin, Royston 2009. 'Introduction'. Glen Creeber, Royston Martin (eds.), Digital Culture: Understanding New Media. Maidenhead: McGraw-Hill Education, 1-10.

Doyle, Gillian 2013. 'Re-Invention and Survival: Newspapers in the Era of Digital Multiplatform Delivery'. - Journal of Media Business Studies 10, 4, 1-20.
Emes, Jutta; Roll, Julia 2016. 'Die Live-Oper im digitalen Zeitalter'. - Carsten Baumgarth, Holger J. Schmidt (eds.), Markentag 2016. Wiesbaden: Springer Gabler, 207-243.

Esch, Franz-Rudolf 2014. Strategie und Technik der Markenführung. München:Vahlen.

Evens, Tom 2010. 'Value Networks and Changing Business Models for the Digital Television Industry.' Journal of Media Business Studies 7, 4, 41-58.

Faulstich, Werner 2004. Medienwissenschaft. Konstanz: UVK Verlagsgesellschaft.

Fetscherin, Marc; Usunier, Jean-Claude 2012 'Corporate Branding: An Interdisciplinary Literature Review'. - European Journal of Marketing 46, 5, 733-753. Föhl, Patrick S.; Lutz, Markus 2011. 'Publikumsforschung in öffentlichen Theatern und Opern.

Nutzen, Bestandsaufnahme und Ausblick. - Patrick Glogner-Pilz, Patrick S. Föhl (eds.), Das Kulturpublikum. Fragestellungen und Befunde der empirischen Forschung. Wiesbaden: VS Verlag für Sozialwissenschaften, 53-125.

Gensler, Sonja; Hinz, Oliver; Skiera, Bernd; Theysohn, Sven 2012. 'Willingness-to-Pay Estimation with Choice-Based Conjoint Analysis: Addressing Extreme Response Behavior with Individually Adapted Designs'. - European Journal of Operational Research 219, 2 . 368-378.

Gere, Charlie 2009. Digital Culture. London: Reaktion Books.

Glaser, Barney; Strauss, Anselm 2008. The Discovery of Grounded Theory: Strategies for Qualitative Research. London: Transaction Publishers.

Hatch, Mary Jo; Schultz, Majken 2002. 'The Dynamics of Organizational Identity'. - Human Relations 55, 8 , 989-1018.

Hatch, Mary Jo; Schultz, Majken 2003. 'Bringing the Corporation into Corporate Branding'. - European Journal of Marketing 37, 7/8, 1041-1064.

Horst, Sven-Ove; Järventie-Thesleff, Rita 2016.

'Finding an Emergent Way through Transformational Change: A Narrative Approach to Strategy'. - Journal of Media Business Studies 13, 1, 3-21.

Horst, Sven-Ove; Moisander, Johanna 2015. 'Paradoxes of Strategic Renewal in Traditional Print-Oriented Media Firms. - International Journal on Media Management 17, 3, 157-174.

Järventie-Thesleff, Rita; Moisander, Johanna; Laine, Pikka-Maaria 2011. 'Organizational Dynamics and Complexities of Corporate Brand Building: A Practice Perspective.' - Scandinavian Journal of Management 27, 2, 196-204.

Jobst, Johanna; Boerner, Sabine 2011. 'Understanding Customer Satisfaction in Opera: First Steps toward a Model:' - International Journal of Nonprofit and Voluntary Sector Marketing 16, 1, 50-69.

Jones, Jennifer 2016. Social Media, Marketing, and the Opera Singer. PhD thesis. Arizona State University. Tempe.

Josch, Moritz 2010. Wie Public Viewing die Oper auf den Kopf stellt. Überlegungen zu einer Medienverschiebung im Opernbereich. München: GRIN Verlag.

Keller, Kevin Lane 1993. 'Conceptualizing, Measuring, and Managing Customer-Based Brand Equity'. Journal of Marketing 57, 1, 1-22.

Keller, Kevin Lane 2005. 'Kundenorientierte Messung des Markenwerts'. - Franz-Rudolf Esch (ed.), Moderne Markenführung. Grundlagen-Innovative AnsätzePraktische Umsetzungen. Wiesbaden: Gabler, 13071327.

Küng, Lucy 2017. 'Reflections on the Ascendancy of Technology in the Media and Its Implications for Organizations and Their Leaders'. - The Journal of Media Innovations 4, 1, 76-81.

Lowe, Gregory Ferrell 2016. 'Introduction: What's So Special about Media Management?' - Gregory Ferrell Lowe, Charles Brown (eds.), Managing Media Firms and 
Industries: What's So Special about Media Management? Heidelberg: Springer, 1-20.

Lutz, Markus 2013. Besucherbindung im Opernbetrieb. Theoretische Grundlagen, empirische Untersuchungen und praktische Implikationen. Wiesbaden: Springer. Malmelin, Nando; Moisander, Johanna 2014 'Brands and Branding in Media Management: Toward a Research Agenda'. - International Journal on Media Management 16, 1, 9-25.

Manovich, Lev 2009. 'The Practice of Everyday (Media) Life: From Mass Consumption to Mass Cultural Production?' - Critical Inquiry 35, 2, 319-331. McDowell, Walter S. 2011. 'The Brand Management Crisis Facing the Business of Journalism. - International Journal on Media Management 13, 1, 37-51. Meffert, Heribert 2012. 'Markenführung im Wandel. Alte Weisheiten und neue Erkenntnisse.' - Christoph Burmann, Tilo Halaszovich, Frank Hemmann (eds.), Identitätsbasierte Markenführung. Wiesbaden: Springer Gabler, 269-273.

Mierzejewska, Bozena; Shaver, Dan 2014. 'Key Changes Impacting Media Management Research: - International Journal on Media Management 16, 2, 47-54. Mottart, André; Soetaert, Ronald; Bonamie, Bart 2004. 'Digitization and Culture'. - Interactive

Educational Multimedia: IEM 8, 24-38.

Olleros, F. Xavier; Zhegu, Majlinda 2016. 'Digital

Transformations: An Introduction'. - F. Xavier Olleros, Majlinda Zhegu (eds.), Research Handbook on Digital Transformations. Cheltenham: Edward Elgar, 1-19. Orme, Bryan K. 2014. Getting Started with Conjoint Analysis: Strategies for Product Design and Pricing Research. Madison: Research Publishers.

Pavlik, John V.; Mclntosh, Shawn 2013. Converging

Media: An Introduction to Mass Communication. Oxford: Oxford University Press.

Phillips, Barbara J.; McQuarrie, Edward F.; Griffin, W. Glenn 2014a. 'The Face of the Brand: How Art Directors Understand Visual Brand Identity'. - Journal of Advertising 43, 4, 318-332.

Phillips, Barbara J.; McQuarrie, Edward F.; Griffin, W. Glenn 2014b. 'How Visual Brand Identity Shapes Consumer Response'. - Psychology \& Marketing 31, 3 , 225-236.

PwC 2016. Streaming the Future: How Will Technology, Media, and Telecommunications Companies Prepare for Further Disruption. S.l.: PricewaterhouseCoopers.

Radtke, Bernd 2013. Markenidentitätsmodelle. Analyse und Bewertung von Ansätzen zur Erfassung der Markenidentität. Wiesbaden: Springer Gabler.

Rao, Vithala R. 2014. Applied Conjoint Analysis. Heidelberg: Springer.

Reed, Thomas Vernon 2014. Digitized Lives: Culture, Power, and Social Change in the Internet Era. Abingdon: Routledge.

Reuband, Karl-Heinz 2013a. 'Der Bayreuther Parsifal im Kino. Das Publikum der ersten Live-Übertragung der Bayreuther Festspiele und dessen Beurteilung der Aufführung und Übertragung ins Kino.' - Wagnerspektrum 2, 185-213.

Reuband, Karl-Heinz 2013b. 'Opern "live” im Kino. Wird durch Opernübertragungen ins Kino ein neues und sozial ausgewogeneres Publikum erschlossen als durch Aufführungen im Opernhaus?' - Sigrid BekmeierFeuerhahn, Karen van den Berg, Steffen Höhne, Rolf Keller, Birgit Mandel, Martin Tröndle, Tasos Zembylas (eds.), Die Kunst des Möglichen - Management mit Kunst. Jahrbuch für Kulturmanagement 2013. Bielefeld: Transcript-Verlag, 223-246.

Reuband, Karl-Heinz 2015. 'Der Besuch von Theatern und Opern in der Bundesrepublik. Verbreitung, Trends und paradoxe Altersbeziehungen'. - Norbert Sievers (ed.), Neue Kulturförderung. Kulturstatistik, Chronik, Literatur, Adressen (Jahrbuch für Kulturpolitik). Essen: Klartext, 359-374.
Reynolds, Thomas J.; Gutman, Jonathan 1988. 'Laddering Theory, Method, Analysis, and Interpretation'. - Journal of Advertising Research 28, 1, 11-31.

Reynolds, Thomas J.; Phillips, Joan M. 2009. 'A Review and Comparative Analysis of Laddering Research Methods. - Review of Marketing Research 5, 130-174. Roll, Julia; Emes, Jutta; Horst, Sven-Ove 2017. 'Cultural Marketing in the Digital Age: The Influence of Place and Media on the Brand Image of Live-Operas. - Journal of Marketing Trends. Forthcoming.

Roll, Julia; Höflich, Joachim R. 2014. Cooperations between Companies and High Culture Institutions: Potentials for Customer Acquisition and Loyalty. An explorative study. Bauhaus-Universität Weimar. Sampson, Peter 1972. 'Using the Repertory Grid Test'. Journal of Marketing Research 9, 1, 78-81.

Schäfer, Hans Jürgen 1967. 'Das Theater und sein Publikum: - Publizistik 12, 4, 207-219.

Siegert, Gabriele; Förster, Kati; Chan-Olmsted, Sylvia M.; Ots, Mart 2015. 'What Is So Special About Media Branding? Peculiarities and Commonalities of a Growing Research Area:. - Gabriele Siegert, Kati Förster, Sylvia M. Chan-Olmsted, Mart Ots (eds.), Handbook of Media Branding. Cham: Springer International, 1-8. Souiden, Nizar; Kassim, Norizan M.; Heung-Ja, Hong 2006. 'The Effect of Corporate Branding Dimensions on Consumers Product Evaluation: A Cross-Cultural Analysis'. - European Journal of Marketing 40, 7/8, 825-845.

Steichen, James 2013. 'Are HD Broadcasts "Cannibalizing" the Metropolitan Opera's Live Audiences?' - OUPblog, 13 August. https://blog.oup. com/2013/08/hd-broadcast-cannibalizationmet-operas-live-audience/ (21 November 2017). Viagas, Robert 2017. 'Metropolitan Opera Announces Live Cinema Broadcast Dates for 2017-18'. - Playbill, 3 March. http://www.playbill.com/article/metropolitanopera-announces-live-cinema-broadcast-datesfor-201718 (21 November 2017).

Voyer, Benjamin G.; Kastanakis, Minas N.; Rhode, Ann Kristin 2017. 'Co-Creating Stakeholder and Brand Identities: A Cross-Cultural Consumer Perspective'. Journal of Business Research 70, 399-410.

Vukanović, Zvezdan 2016. 'Business Model Research Agenda Positioning: Conceptual Frameworks, Functions, Benefits, Rationale, Dynamics, Performance, and Economic Feasibility'. - Foreign Direct Investment Inflows into the South East European Media Market: Towards a Hybrid Business Model. Cham: Springer International, 5-66.

Weinacht, Stefan 2015. 'Marketing Communication of Media Brands: A Literature Review'. - Gabriele Siegert, Kati Förster, Sylvia M. Chan-Olmsted, Mart Ots (eds.), Hand book of Media Branding. Cham: Springer International, 231-249.

Wirtz, Bernd W.; Pelz, Richard; Ullrich, Sebastian 2011. 'Marketing Competencies of Publishers and Ad Sales Success: An Empirical Analysis'. - Journal of Media Business Studies 8, 1, 23-46.

Woolfe, Zachary 2012. 'I'm Ready for My Close-Up, Mr. Puccini'. - The New York Times, 27 April. http://www.nytimes.com/2012/04/29/arts/music/ the-mets-hd-broadcasts-are-changing-opera.html (21 November 2017). 